\title{
PARA UMA INTERPRETAÇÃO DO CONCEITO DE CIDADANIA EM JOSÉ SARAMAGO: UMA APROXIMAÇÃO À LEITURA DE ENSAIO SOBRE A CEGUEIRA E ENSAIO SOBRE A LUCIDEZ
}

\author{
A CONCEPT INTERPRETATION OF CITIZENSHIP IN JOSÉ \\ SARAMAGO: A READING INTRODUCTION OF BLINDNESS \\ AND SEEING
}

PARA UNA INTERPRETACIÓN DEL CONCEPTO DE CIUDADANÍA EN JOSÉ SARAMAGO: UNA APROXIMACIÓN A LA LECTURA DE ENSAYO SOBRE LA CEGUERA Y ENSAYO SOBRE LA LUCIDEZ

Maria de Lourdes Pereira

Universidad de las Islas Baleares

\section{ABSTRACT}

José Saramago's work constitutes a privileged example to understand the way that literature could be a reality interpretation proposal. In this article we propose a parallel reading of Blidness and Seeing. According to the events that cause us distress, we verify how it urges to rethink and restructure the concept of active citizenship. Dismissing a defeatist or pessimistic point of view, José Saramago's work can be an excellent example of how literature, culture and thinking can contribute for the edification of a clear and responsible democratic society, which claims an increasing consciousness of the individual ethical attitude. Citizenship is an increasing decisive factor in societies functioning. We should be conscious that only thinking 
can help us avoid future society to definitely get installed in the utopia domain and make society even closer and more real.

Key words: José Saramago, Blindness, Seeing, Portuguese literature, citizenship

\section{RESUMO}

A obra de José Saramago constitui um exemplo privilegiado para entender o modo como a literatura pode vir a constituir uma proposta de interpretação da realidade. Neste trabalho propomos uma leitura paralela de Ensaio sobre a cegueira e Ensaio sobre a lucidez para, à luz dos acontecimentos que nos afligem, verificar como urge repensar e reconfigurar o conceito de cidadania activa. Afastando-nos de uma perspectiva derrotista ou pessimista, a obra de José Saramago pode ser um excelente exemplo de como a literatura, a cultura e o pensamento podem concorrer para a edificação de uma sociedade democrática esclarecida e responsável que reclama do indivíduo uma postura ética cada vez mais consciente. A cidadania é, cada vez mais, um factor decisivo na orgânica das sociedades e devemos ser conscientes de que só o pensamento nos pode ajudar a evitar que a sociedade do futuro se instale definitivamente no domínio da utopia, tornando-a cada vez mais, mais próxima, mais real.

Palavras-chave: José Saramago, Ensaio sobre a cegueira, Ensaio sobre a lucidez, Literatura portuguesa, Cultura portuguesa, cidadania

\section{RESUMEN}

La obra de José Saramago constituye un ejemplo privilegiado para entender el modo como la literatura puede llegar a constituir una propuesta de interpretación de la realidad. En este trabajo proponemos una lectura paralela de Ensayo sobre la ceguera y Ensayo sobre la lucidez para, a luz de los hechos que nos afligen, verificar como urge repensar y reconfigurar el concepto de ciudadanía activa. Distanciándonos de una perspectiva derrotista o pesimista, la obra de José Saramago puede ser un excelente ejemplo de como la literatura, la cultura y el pensamiento pueden concurrir para la edificación de una sociedad democrática clara y responsable que reclama al individuo una postura ética cada vez más consciente. La ciudadanía es, cada vez más, un factor decisivo en la orgánica de las sociedades y debemos ser conscientes de que solamente el pensamiento nos podrá ayudar a evitar que la sociedad 
Para uma interpretação do conceito de cidadania em José Saramago: uma aproximação à leitura de Ensaio sobre a Cegueira e Ensaio sobre a Lucidez Maria de Lourdes Pereira

\section{an}

Ue Actionova: Revista de TEORÍA DE LA LITERATURA Y LITERATURA COMPARADA, Monográfico 3: 113-129 DOI: http://doi.org/10.15366/actionova2019.m3.007

del futuro se instale definitivamente en el dominio de la utopía, volviéndola cada vez más, más cercana, más real.

Palabras clave: José Saramago, Ensayo sobre la ceguera, Ensayo sobre la lucider, Literatura portuguesa, Cultura Portuguesa, ciudadanía

Fecha de recepción: 18 de noviembre de 2019.

Fecha de aceptación: 11 de diciembre de 2019.

Cómo citar: Pereira, Maria de Lourdes (2019): «Para uma interpretação do conceito de cidadania em José Saramago: uma aproximação à leitura de Ensaio sobre a cegueira e Ensaio sobre a lucides?, en Actio Nova: Revista de Teoría de la Literatura y Literatura Comparada, Monográfico 3: 113-129. DOI: https://doi.org/10.15366/actionova2019.m3.007 
A publicação de Ensaio sobre a lucidez, em 2004, não podia deixar de provocar no leitor mais ou menos atento à obra de José Saramago a necessidade de estabelecer um paralelismo entre este título e o de Ensaio sobre a cegueira. Torna-se evidente que o ensaio então publicado vinha interpelar a nossa leitura da obra que conhecêramos três anos antes de o autor português ser reconhecido com o Prémio Nobel da literatura; Ensaio sobre a cegueira (1995). Nessa correlação há que sublinhar ainda a presença do termo ensaio, o qual nos remete para as questões de género. Contudo, convém ir já adiantando que estamos longe de que estes títulos estabeleçam qualquer correlação entre a obra e o género literário que as possa definir, tratando-se antes de mais um jogo literário que o autor estabelece com o seu leitor e sempre ao serviço de uma leitura ativa, em que o leitor é sempre um elemento fundamental. Em Ensaio sobre a lucider, tal como sucedera quase uma década antes com Ensaio sobre a cegueira, não vamos encontrar propriamente os resultados de uma análise ou de um estudo sobre uma realidade, antes a exposição, ou a narração, de factos que confinam essa realidade mas, isso sim, apelando sempre ao espírito crítico de um leitor que, a qualquer momento, inicie uma discussão sobre o que lhe é apresentado, competindo-lhe a ele a concretização desse ensaio, propriamente dito. Paralelamente, não podemos ignorar que a nossa leitura se acabará por estabelecer sempre em função de uma dualidade constante. Como vem sendo característico da obra saramaguiana, não nos podemos esquecer de que o jogo que o escritor cria com o leitor implica, frequentemente, a leitura da obra do autor como um todo, e não como uma mera sucessão de títulos independentes. É neste sentido que devemos permanecer atentos porque, se por um lado somos tentados a ler Ensaio sobre a cegueira como a primeira parte de uma narrativa mais vasta, por outro, não devemos ignorar que ambas as obras podem constituir duas narrativas autónomas e fechadas, mas sempre dentro da máxima do próprio autor quem, em conversa com Carlos Reis, nos chamou um dia a atenção para a necessidade de termos sempre em conta que «a história é parcial e é parcelar. É parcelar, porque conta uma parte apenas daquilo que aconteceu. Há que, evidentemente, relacionar História, tempo, passado...» (Reis, 1998:79). Cabe, pois, atender sempre aos fatores que se prendem com a subjetividade do narrador/autor, e sobretudo com a nossa memória civilizacional. Afinal, só ao leitor competirá corroborar, ou não, essa ligação efetiva entre as duas obras a partir dos elementos que lhe são revelados.

No nosso caso, e fazendo gala da nossa condição de leitores, sentimo-nos já plenamente legitimados para a construção da nossa leitura de Ensaio sobre a lucidez a partir de 
Ensaio sobre a cegueira, e procedermos depois à estruturação desse ensaio que, mais ou menos explicitamente, encerram essas duas obras.

A partir das vivências dos seus protagonistas, Ensaio sobre a cegueira constitui um relato direto, que em determinados momentos chega mesmo a ser duro e dramático, dessa realidade em que sucumbiu uma sociedade afetada por um surto de cegueira que, como se de um vírus se tratasse, se foi transmitindo por todos os habitantes de uma cidade. Esse surto surge um belo dia, sem se saber como nem porquê, e levando as autoridades a tomar conta das vidas de toda essa multidão que se vai formando, confinando-a a viver entre muros, encarcerada e isolada, distante do humanismo que definiria qualquer sociedade minimamente estruturada. Para além da privação de liberdade a que a cegueira conduz todos esses indivíduos, vamos observando como a organização das autoridades competentes prima pela sua ineficácia. As condições em que assentará a organização dessa micro-sociedade de invisuais são tão débeis e frágeis que esses sujeitos acabarão por ser arrastados para os limites mais atrozes da humanidade, na fronteira com aquilo que consideraríamos já mesmo como próprio do desumano, e que o autor retrata fazendo uso de domínios como o escatológico, ou até mesmo o criminal. Até que recuperem a vista estes cidadãos terão de aprender a assumir a sua cegueira, e também a ver o mundo desde dentro, e não só a partir das evidências. No fundo, terão todos de passar por um longo e árduo processo de aprendizagem que os conduza à descoberta da importância de todos os sentidos num único corpo; terão de valorizar a plenitude dos sentidos, em detrimento da supremacia de um único, como possa ser a visão. Ao longo desse processo, os cidadãos aprenderão ainda a suavizar essa segunda pele que cobre os seres humanos e que é o egoísmo. Durante esse período, em que vivem privados da visão, será fundamental a presença e a ação da mulher do médico, a única que ficara imune ao contágio e que, apesar de poder ver com os seus próprios olhos, terá também de aprender a ver desde dentro, desde os outros sentidos, a viver nesse mundo de cegueira. No princípio, só o marido conhece o seu segredo, mas torna-se-lhe impossível esconder a sua realidade pelo que acabará, progressivamente, por ter de revelar aos outros que é a única que vê entre todos eles. A sua realidade é uma prova constante de resistência e de sobrevivência porque, apesar de tudo, acabaremos por entender o quão difícil é ser diferente da maioria homogénea que nos rodeia, mesmo que, inicialmente, pensemos estar numa situação de vantagem, como é o caso da mulher do médico. Mas este contexto permitirá, por seu lado, que o grupo aprenda a reconhecer a importância de um outro que os ensine a ver 
e a descobrir que «estariam cegos dos olhos, mas não do entendimento» (Saramago, 1998: 256).

Este pode ser precisamente um dos pontos de articulação entre as duas obras que agora nos ocupam; depois de termos alcançado esse patamar capaz de nos conduzir iminentemente a um estado de desumanização, e perante o caos em que se transformou a nossa sociedade, só nos resta empreender um processo que nos restitua a lucidez necessária para que possamos recuperar a humanidade, já tão manchada, conscientes de que tal só será possível mediante o exercício do pensamento e da especulação provocados pela realidade (re)apresentada porque, tal como no-lo adverte José Gil: «Na filosofia, o pensar molda e submete o conhecer - ou, simplesmente, utiliza-o para os seus próprios fins, sem lhe tocar» (Gil, 2019: 17). Assim sendo, inferimos que a chuva será um elemento de união perfeito entre as duas narrativas, ou a cortina que oscila entre a cegueira e a lucidez; se em Ensaio sobre a cegueira só ela poderá limpar e purificar a cidade de tanta sujidade, depois do duro surto de cegueira branca, em Ensaio sobre a lucidez, será o mau tempo que desencadeará um conflito democrático. Convocados para votarem, inicialmente os cidadãos tomam a iniciativa de se absterem de exercer o seu voto porque chove torrencialmente. Perante a preocupação daqueles que zelam pelo normal decorrer das eleições, esse será o primeiro sintoma da fragilidade da democracia, a qual se pode ressentir até mesmo de algo tão natural como um dia de chuva. Aliás, as primeiras palavras da obra são bastante reveladoras do mau tempo que se abate sobre a nossa democracia: «Mau tempo para votar, queixou-se o presidente da mesa da assembleia eleitoral (...)» Saramago (2014: 9). Com o passar das horas, a chuva abrandará e os cidadãos acudirão às urnas. A surpresa virá depois com o escrutínio dos votos e a constatação de que $70 \%$ desses votos são em branco. Perante o desconforto dos partidos, as autoridades decidem repetir o processo de votação e, no final, $80 \%$ dos eleitores decidirá votar em branco.

Estes resultados irão desencadear o início de toda a intriga, uma vez que as autoridades se empenharão em descobrir o culpável deste ataque a uma «democracia consolidada, tal a nossa» (Saramago, 2014: 299) porque, forçosamente, terá de o haver; a culpa terá sempre de cair sobre alguém que se situará forçosamente no ponto oposto ao nosso. Assim, como leitores, estamos já advertidos por uma série de indícios, e antes de avançarmos para mais peripécias, estamos em condições de antever aqui uma nova cegueira branca, a qual o texto se encarregará de corroborar posteriormente, sendo várias as alusões 
a essa cegueira física que vitimara os habitantes da sociedade retratada em Ensaio sobre a cegueira, quatro anos antes: «o senhor ministro da cultura acertou em cheio ao comparar a praga que estamos padecendo a uma nova forma de cegueira» (Saramago, 2014: 191). Perante a tentativa falhada de conseguir averiguar a verdade através de interrogatórios, resta ao governo usar o poder para conseguir encontrar esse culpado, que estará sempre do outro lado.

Ora, esta identificação entre a crise provocada pelo uso massivo do voto em branco e a cegueira branca estabelece-se também, em grande parte, pela implicação da linguagem na construção do texto e no trabalho de decifração do mesmo. Um dos pontos fulcrais por que se bate a escrita de José Saramago é sempre o de apelar à necessidade de entendermos a linguagem em propriedade, com sumo cuidado, e de permanecermos atentos ao eco que as palavras lançam, e que nos trarão a tão procurada lucidez; também nós devemos seguir a lição do inspetor de polícia quem nos revela que «aprendi da experiência deste ofício que as meias palavras existem para dizer o que as inteiras não podem» (Saramago, 2014: 300). Seguindo as palavras do próprio José Saramago, vamos reconhecendo a leitura como um trabalho de dedicação pelo que acabaremos por colocar também a hipótese de «se o mundo não seria um pouco mais decente se soubéssemos como reunir umas quantas palavras que andam por aí soltas» (Saramago, 2014: 318). Num evidente exercício metalinguístico, o escritor/narrador manifesta uma atenção particular com o leitor, seja imprimindo um ritmo próprio à sua escrita, seja fazendo referência a algum ponto que lhe permita criar entre ambos alguma empatia, seja, inclusive, invocando-o ou interpelando-o com o intuito permanente de que, resistindo, saiba interpretar as palavras para ser capazes de as ler em toda a sua plenitude; ou seja, que «os leitores leiam a notícia até ao fim» (Saramago, 2014: 337).

Como vemos, as questões sobrepõem-se à narrativa para exigirem ao leitor que veja, observe e interprete a realidade retratada, ou seja, que pense, em função de uma articulação dos modos de representação da realidade, e que muito devem ao uso da linguagem porque, como muito bem o aponta Miguel Real:

o romance ganha em José Saramago um estatuto ensaístico de permanente inquirição e abertura de horizontes culturais, segundo interrogações radicais de caracter filosófico (a questão de Deus, a questão civilizacional do capitalismo, a questão da identidade do eu...) que desafiam, senão subvertem, o paradigma conceptual por que habitualmente interpretamos o mundo, forçando o romance a tornar-se, mais do que a narrativa de uma história, um inquiridor das regras e dos modelos do acto instaurador da palavra (Borges, 2010: 9-10). 
Seguindo este processo, em breve, o leitor reconhecerá nos dados narrados uma realidade própria, em que se cruzam memórias e vivências atuais, pelo que se desencadeará um processo de análise odontológico provocado por toda essa narrativa. Em determinados momentos, esses ecos vivenciais aproximam-nos de uma engrenagem literária própria do romance policial, ou até do romance psicológico. Se por um lado se apela ao nosso espírito detectivesco, ao nosso espírito crítico, por outro pressentimos um certo efeito psicológico que se estabelece desde a teia que se vai urdindo a partir dos diálogos e dos episódios narrados, assim como dos recursos literários que acabarão, obviamente, por adensar a identificação entre o texto e o leitor, fazendo com que este se sinta cada vez mais implicado no devir da narrativa. Esta teia torna-se ainda mais densa com a presença, não só de referências ao já referido surto de cegueira ocorrido quatro anos antes, mas também com a presença de outros referentes, como possam ser as personagens; desde a mulher do médico até ao cão. Esta presença obriga-nos a repensar a nossa leitura e a abrir as nossas interpretações, não só em função da obra que estamos a ler, mas também da que já lemos. A irrupção das personagens e das suas circunstâncias na história contribui também para essa atmosfera de empatia que se vai criando entre o leitor e o texto, uma vez que as pressentimos como mais dinâmicas e estimulantes, cuja realidade identitária não se esgotou apenas numa obra.

Em ambas as obras as coordenadas espácio-temporais são bastante indefinidas, não havendo praticamente referentes concretos, e a referência mais precisa será aquela que aponta para os quatro anos que medeiam entre as duas narrativas. Não obstante, apesar dessa indefinição espácio-temporal, e sobretudo em Ensaio sobre a lucider, existem alguns elementos que nos permitem estabelecer uma correlação algo simbólica com um discurso próprio de um tempo que os portugueses facilmente identificarão. O tom do discurso político, ou as referências à emissão televisiva, podem conduzir a nossa memória até aos tempos do antigo regime. Mas estas alusões não são senão meros recursos falaciosos, sem um perfil cronológico definido, embora sob o mesmo tom político. A escrita saramaguiana exige-nos que permaneçamos atentos aos pormenores, assim, a par de um discurso dogmático que identificamos frequentemente com o dos tempos prévios à democracia, ou das descrições que nos evocam a memória ou os relatos da sucessão dos acontecimentos vividos em Lisboa na madrugada de 24 para 25 de abril de 1974, tropeçamos até mesmo com a alusão a uma cadeira que nos resulta demasiado familiar: «mas o maior erro da minha vida como político 
foi permitir que me sentassem nesta cadeira, não percebi a tempo que os braços dela têm algemas» (Saramago, 2014: 211). Não faltará também uma referência ao quotidiano desses tempos a preto e branco em que «o ecrã da tevê mostrava ainda a mira fixa, era demasiado cedo para o início da emissão». (Saramago, 2014: 171). Simultaneamente, neste tempo simbólico, em que eras democráticas lutam por se sobreporem a um edifício velho e caduco, surge a referência a um célebre e mais recente chefe do governo, e posteriormente presidente da república: «Não direi como o outro, que nunca me engano e raramente tenho dúvidas, mas quase, quase» (Saramago, 2014: 209).

Apesar de tudo, estes referentes não estabelecem qualquer vínculo espáciotemporal o que, aliado a uma identificação tipificada das personagens, acabará por nos instalar num tempo alegórico que, por um lado, nos permite lê-lo como metáfora ou parábola dos dias que vivemos e, por outro, nos insiste na necessidade de revermos e interpretarmos as causas de um processo de esgotamento democrático que nos afeta há já muito tempo e que, aparentemente, ignoramos. Aliás, se em Ensaio sobre a cegueira os acontecimentos podem assumir um tom mais simbólico, em Ensaio sobre a lucidez, a coincidência entre a realidade que vivemos hoje e os acontecimentos que suportam a trama da obra poderiam mesmo inscreverse no domínio do profético. Não obstante, esse espírito visionário de José Saramago não é senão fruto de um complexo e estruturado processo de observação e de indagação da realidade. Esta será precisamente a base da modernidade, atualidade e universalidade de toda a sua obra.

Não nos resulta difícil identificar esta crise gerada pelo uso massivo do voto em branco com a cegueira branca, já que ambos os episódios constituem uma reação/consequência a um estado de esgotamento e de tensão dos limites das normas estabelecidas, sejam elas sociais, humanistas ou políticas, da mesma forma que, aludindo ao poder da analogia, podemos transferir a cegueira branca do voto em branco para a abstenção que atinge perigosamente a nossa democracia, que chega a atingir níveis que nos podem levar a repensar as questões inerentes à aplicação do voto num regime democrático, criamos nós, maduro.

Chegamos assim ao momento em que, não só como leitores, mas, e sobretudo, como cidadãos, nos interrogamos do porquê do esgotamento da nossa democracia, do sistema político mais perfeito que conhecemos. O nosso juízo estabelece-se a par da leitura, onde percebemos esses discursos demagógicos de uma classe política que, com o tempo, 
soube manipular as leis e o sistema estabelecido, não só para servir a sociedade, mas também para se servir a si próprio. Seria necessário revisitar e reinterpretar o conceito de democracia herdado desde a antiga Grécia. Tal como o apontávamos antes, urge repensar as palavras e os conceitos, em função das realidades por elas nomeadas, sem permitir que estas se esvaziem ou percam o seu referente concreto. A democracia nasce precisamente com o desejo de que todos os cidadãos possam intervir no desenvolvimento das sociedades elegendo os seus representantes, dinâmica que se parece ter vindo a esgotar para, em nome dessa confiança que a democracia inspiraria, se cometerem excessos de toda a índole. Ao longo da obra assistimos a discursos demagógicos, assentes numa retórica vazia, que deixam em evidência os abusos cometidos pelo poder contra as liberdades individuais ou em favor de interesses privados. A denúncia que aqui é feita adensa-se ainda mais pelo tom irónico empregue, que chega mesmo a roçar o sarcástico, e que exige do leitor a capacidade de reconfiguração da realidade desde uma dinâmica inversa:

O senhor primeiro-ministro sabe melhor que ninguém que nenhum ministro do interior, em qualquer época e em qualquer país do mundo, abriu alguma vez a boca para falar das misérias, das vergonhas, das traições e dos crimes do seu ofício, portanto, pode ficar descansado, também neste caso não serei uma exceção (Saramago, 2014: 146).

A hipocrisia do sistema político, que no início parece ignorar absolutamente o poder que uma cidadania responsável e participativa possa assumir, acaba por estremecer quando surge a suspeita de que se possa ter organizado alguma reação:

Disse que o voto em branco poderia ser apreciado como uma manifestação de lucidez por parte de quem a usou. Como se atreve, em pleno conselho do governo, a pronunciar semelhante barbaridade antidemocrática, deveria ter vergonha, nem parece um ministro da justiça, explodiu o da defesa (Saramago, 2014: 191).

Estes relatos não nos deixam muitas dúvidas quanto ao nervosismo instalado nas altas instâncias governativas relativamente a essa cegueira branca, nem quanto ao tom ditatorial de um discurso que não se repercute apenas nas medidas de repressão e de perseguição que o estado adotará para averiguar quem é o culpado de tal ameaça para o país, e assim estabelecer a ordem, a partir de um ambiente de contenção e de medo, mas também na própria estrutura interna do governo: «O primeiro ministro olhou em redor, é este o meu 
plano, disse, submeto-o ao vosso exame e à vossa discussão, mas, escusado será dizê-lo, conto que seja aprovado por todos» (Saramago, 2014: 83). Este governo, que deveria representar a vontade dos seus cidadãos, não tem nenhum pudor em deixar em evidência o quão viciadas estão as regras do poder. Aliás, esta parece ser uma ideia generalizada dentro do próprio sistema e sempre que alguém se atreva a discordar é logo reconduzido, e apenas lhe compete concordar e apoiar as decisões, dentro de uma hierarquia previamente estabelecida: «O seu sucessor sou eu, quem já é ministro da justiça também pode ser ministro do interior, fica tudo em casa, eu me encarregarei» (Saramago, 2014: 356). Perante este estado endogâmico, as medidas a tomar serão sempre o reflexo dessa atitude absolutista, de quem se crê no direito de poder fazer tudo para salvar a nação, sem que se tenha em consideração que num estado democrático a política da nação deve ser traçada pelos desígnios do conjunto dos seus cidadãos. Na linha de tudo isto, invertendo os vetores hierárquicos, este modelo de estado nunca teme nada nem ninguém; nem a reação dos seus cidadãos nem a fiabilidade da sua política, já que, em último recurso, quando as estratégias não se aliam com as suas vontades, resta sempre essa última solução que lhes permite lavar as mãos, como Pilatos: «Se não o conseguirmos, o governo demite-se» (Saramago, 2014: 172).

Mas esta cegueira branca, enquanto reação ao estado a que a nossa democracia foi conduzida, suscita-nos outras questões, que se prendem precisamente com essa base em que assenta o poder democrático e que são justamente os cidadãos. Enquanto leitores, e apelando sempre à nossa liberdade ética, a que nos assiste no momento de edificação de uma cidadania responsável, e enquanto cidadãos de um tempo que se identifica em muitos pontos com as peripécias desta obra, ocorre-nos a questão de se a votação em branco deve ser entendida como uma reação ativa ou, antes, passiva.

O cansaço do processo democrático é algo evidente aos olhos de todos. Os abusos, a inoperância e incompetência, a falta de estratégias eficazes, a par da repressão e da violação das liberdades individuais, sempre em nome da democracia, acabarão, inevitavelmente, por cegar uma cidadania, já cansada de contemplar uma situação que apenas a queima, sem que se consiga vislumbrar nenhum feixe de luz no horizonte. A partir desta análise, podemos todos perceber que o estado a que se chegou muito tem que ver com a confiança cega que o poder tem depositado na cidadania, desvalorizando, e até mesmo desprezando, a sua capacidade de reação: 
tanto mais que a declaração do estado de exceção, de que tanto se esperava, não havia produzido qualquer efeito percetível no sentido desejado, porquanto não tendo os cidadãos deste país o saudável costume de exigir o regular cumprimento dos direitos que a constituição lhes outorgava, era logico, era mesmo natural que não tivessem chegado a dar-se conta de que lhos haviam suspendido. Impunhase, por conseguinte, a imposição de um estado de sítio a sério, que não fosse uma coisa para inglês ver (Saramago, 2014: 66).

A esta confiança cega por parte do poder, há que somar a sua inoperância, desorganização, falta de preparação de estratégias e o abuso da demagogia retórica. Em nosso entender, e perante esta situação cabem duas possibilidades. A primeira, e talvez a mais imediata, será uma reação massiva por parte da cidadania, contra todas as previsões e tendo em conta a tradição dos brandos costumes. Mas já no-lo adverte o próprio José Saramago em $O$ Homem duplicado que tenhamos cuidado com a ira dos mansos, cujos efeitos podem ser bastante perniciosos:

O mais normal é que dure pouco, mas dá medo quando se manifesta. Por isso, para muita gente, a prece mais fervorosa, na hora de ir para a cama, não é o consabido pai-nosso ou a sempiterna ave-maria, mas sim esta, Livrai-nos, Senhor, de todo o mal, e em particular da ira dos mansos (Saramago, 2002: 4647).

Ora, já avisados deste perigo, não nos restam dúvidas de que a cegueira branca pode ser interpretada como sendo o despertar dessa ira. Por fim, os mansos também se enfurecem e, sem faltarem às leis que desejam cumprir, fazem do voto em branco a sua arma de revolta contra uma situação angustiante e castradora. Essa solidez social controlada pode romper-se em qualquer momento e, obviamente, a paz social entra em risco de um colapso iminente. O cidadão, embora manso, sente que urge tomar alguma decisão que provoque o abalo de uma estrutura assente numa ilusória estabilidade. As palavras de José Saramago permitemnos, então, ir ao encontro de um caminho de revelação ou de lucidez humanista de que nos fala José Rui Teixeira e a que devemos permanecer atentos: «Parece certo que a literatura mesmo sem um compromisso especificamente soteriológico - gosta de conduzir o homem para o desassossego da salvação» (Teixeira, 2019: 73). A par da ira dos mansos, que nos poderá despertar da modorra em que nos instalamos/instalaram, não podemos ignorar que a salvação não passa pela comiseração ou pela inação, mas antes pelo desassossego e talvez seja este o momento decisivo para essa tomada de consciência por parte de todos. 
Não obstante, chegados a este ponto, surge ainda outra questão bastante pertinente. Num sistema democrático, o voto em branco acaba por se traduzir sempre numa demissão de cidadania; assim, esta abnegação por parte do eleitor não será senão a manifestação da sua passividade e, até mesmo, da sua resignação.

Fazendo gala da sua sábia ironia, linguagem que José Saramago tão bem entende e domina, o surrealista Fernando Lemos afirmava que devemos ter em conta que quando «Você não vota, passa a ser ocultação de morte. É um vivo ou um morto que não comparece.» ${ }^{1}$ (Lemos, 2019: 348). Ora, é precisamente esta falta de comparência que nos leva a pensar no papel que cada um de nós deve assumir na construção de uma sociedade equilibrada e sã. A nossa demissão com relação aos nossos deveres pode vir a causar sérias consequências e, nesse sentido, Ensaio sobre a lucidez parece apelar diretamente à necessidade de entendimento por parte de todos quantos fazemos parte da democracia. Votar não é só um dever, muitas vezes conquistado pela luta de muitos, mas, e sobretudo, uma responsabilidade que qualquer cidadão deve exercer com a máxima lucidez:

Não lhe parece que um ato importante como é o de votar deveria merecer de todos os eleitores com sentido de responsabilidade uma expressão grave, séria, compenetrada, ou considera que a democracia dá vontade de rir, Ou talvez pense que a democracia dá vontade de chorar, Que lhe parece, de rir ou de chorar. Só a nossa consciência de cidadania poderá evitar a morte do sistema político mais perfeito que conhecemos; só a nossa lucidez poderá evitar que a cegueira se apodere das nossas sociedades e permita que as nossas cidades sejam tomadas por aqueles que nos querem impor a sua verdade (Saramago, 2014: 52).

A nossa liberdade também é frágil e, precisamente por isso, devemos ser conscientes de que ela implica o cumprimento dos nossos deveres, e entre eles está o de não nos demitirmos da nossa condição de cidadãos ativos, empenhados na recondução de um modelo de sociedade que se tem vindo a esgotar. Talvez seja o momento de reclamar essa necessidade que se impõe de aprendermos a ver para dentro e de nos interrogarmos sobre a realidade que temos e a que queremos ter, com toda a lucidez possível. José Saramago sublinha muitas vezes a necessidade de repensar as denominações em função da realidade por elas representadas, pelo que temos de aprender a ler e a interrogar os significados e os significantes em função das novas configurações que assumem:

\footnotetext{
${ }^{1}$ Estas palavras são proferidas numa entrevista conduzida pelo realizador Victor Ferreira Rocha, realizada no
} Brasil em março e maio de 2018, e inserida em Fernando Lemos, Poesia: 2019. 
É interessante observar, disse, como os significados das palavras se vão modificando sem que nos apercebamos, como tantas vezes as utilizamos para dizer precisamente o contrário do que antes expressavam e que, de certo modo, como um eco que se vai perdendo, continuam ainda a expressar (Saramago, 2014: 67).

As palavras não são recipientes vazios, esgotadas de conteúdo, logo, cabe-nos interrogá-las para que continuem a representar aquilo que a nossa lucidez dite que devem representar, sob o risco de se tornarem inúteis ou, pior ainda, usadas com propósitos alheios à sua configuração e, tal como o senhor Silva o faz em a máquina de fažer espanbóis, de Valter Hugo Mãe, a propósito dos tempos do Estado Novo, urge perseguir uma lucidez que nos permita ver que, afinal, tudo não passa de uma engrenagem superior, permitida por um sistema com o qual terminaremos por ser coniventes:

tudo era para que praticássemos cidadania nenhuma e nos portássemos apenas como engrenagem de uma máquina a passar por cima dos ombros, complexa e grande de mais para lhe percebermos o início, o fim e o fito de cultivar a soberba de um só homem. tudo contribuía para essa cidadania de abstenção (Mãe, 2010: 203).

Ora, esta lucidez que exibe a reflexão do Sr. Silva, a propósito do regime salazarista, acaba por ir ao encontro desse desassossego literário que reclamávamos antes e que a leitura cruzada de Ensaio sobre a cegueira e Ensaio sobre a lucidez desencadeou. Afinal, a literatura e o conhecimento acabarão por nos ajudar a recuperar uma lucidez universal, embora modalizada por tempos próprios, só o pensamento nos permitirá combater esta cegueira branca.

Chegados a este ponto, cabe pensar Ensaio sobre a lucidez na linha de uma distopia. Se nos demitirmos das nossas obrigações enquanto cidadãos, se não vigilarmos pelo estado da nossa democracia, é bem possível que o que nos reste seja essa sociedade (por agora) imaginária onde reina a opressão e a tirania. O tom satírico, ou sarcástico, empregue por José Saramago acabaria por ganhar uma outra dimensão e, nesse caso, seria muito mais complicado recuperar a plenitude dos sentidos. Citando novamente José Gil, e ainda sob o eco das Odes Modernas de Antero de Quental, «Pensar tornou-se perigoso para a sociedade da performance. Pensar é revolucionário» (Gil, 2019: 43). Efetivamente, só o pensamento nos permitirá intervir, no presente, para que a parábola que José Saramago nos apresenta nestes 
dois ensaios não seja uma promessa de futuro mas antes o início de um caminho de progresso conscientes de que, como o refere Richard Rorty «o progresso moral existe, e esse progresso vai efetivamente na direção de uma maior solidariedade humana» (1994: 239). Ora, aqui pode estar precisamente a chave do ensaio que nos propusemos formular logo no início da nossa leitura das duas obras de José Saramago que aqui nos ocupam. Embora instalados na linha da distopia, as palavras do prémio Nobel, precisamente pelo seu poder de desassossegantes, podem abrir um caminho de esperança na edificação de uma renovada cidadania. Uma cidadania que, curada da sua cegueira, será agora mais responsável porque plenamente consciente do seu poder na engrenagem de uma estrutura social; uma cidadania que crescerá na lucidez e no esclarecimento que a literatura, o conhecimento e o pensamento lhe proporcionarão. Então, uma vez alcançado este estádio, será possível evitar que essa distopia que agora se vislumbra no nosso horizonte se transforme em realidade. Contudo, sejamos realistas, não permitamos que o progresso moral se mantenha como uma constante utopia porque é incumbência de cada um de nós, no âmbito dessa solidariedade humana que reclama Richard Rorty, zelar pelo bom funcionamento de uma estrutura social que, apesar do aspeto robusto e sólido, acusa uma grande fragilidade; uma realidade que identificamos com uma sociedade democrática. 
Para uma interpretação do conceito de cidadania em José Saramago: uma aproximação à leitura de

BIBLIOGRAFÍA

Borges, António José (2010): José Saramago, da cegueira à lucidez, Sintra, Zéfiro.

Gil, José (2019): Trajetos filosóficos, Lisboa, Relógio d’água.

Lemos, Fernando (2019): Poesia, Porto, Elogio da sombra, Porto Editora.

Mãe, Valter Hugo (2010): A máquina de fazer espanhóis, Lisboa, Alfaguara.

Reis, Carlos (1998): Diálogos com José Saramago, Lisboa, Caminho.

Rorty, Richard (1994): Contingência, Ironia e Solidariedade, Lisboa, Editorial Presença.

Saramago, José (1995): Ensaio sobre a cegueira, Lisboa, Caminho

Saramago, José (2014): Ensaio sobre a lucidez, Porto, Porto Editora, $6^{a}$ edição.

Saramago, José (2002): O Homem Duplicado, Lisboa, Caminho.

Teixeira, José Rui (2019): Vestigia Dei, Uma leitura teotopológica da literatura portuguesa, Porto, Cosmorama. 


\section{SOBRE LA AUTORA}

\section{María de Lourdes Pereira}

Licenciada em Línguas e Literaturas Modernas pela Faculdade de Letras da Universidade de Lisboa e doutorada pela Universitat de les Illes Balears com uma Tese sobre as relações literárias e Culturais entre Portugal e Espanha (Antero de Quental y la Generación del 70 en el diálogo peninsular). Dirige a Cátedra Mário Cesariny da UIB, onde é docente de língua, literatura e cultura portuguesas, e tem dividido o seu interesse entre a literatura e a língua, com atenção especial para o ensino de Português a estrangeiros. Além da publicação de materiais didáticos de PLE, tem centrado o seu trabalho nos períodos e autores que configuram uma etapa que se inicia com as gerações da segunda metade do siglo XIX até à contemporaneidade.

Contact information: lourdes.pereira@uib.es 